\title{
An analysis of medical students' reflective essays in problem-based learning
}

\section{Jihyun $\mathrm{Si}$}

\author{
Department of Medical Humanities, Dong-A University College of Medicine, Busan, Korea
}

Purpose: This study aimed to explore students' learning experience in problem-based learning (PBL) particularly in terms of what they learned and how they learned in one Korean medical school by analyzing their reflective essays with qualitative research methods. Methods: This study included 44 first-year medical students. They took three consecutive PBL courses and wrote reflective essays 3 times anonymously on the last day of each course. Their reflective essays were analyzed using an inductive content analysis method.

Results: The coding process yielded 16 sub-categories and these categories were grouped into six categories according to the distinctive characteristics of PBL learning experience: integrated knowledge base, clinical problem solving, collaboration, intrinsic motivation, self-directed learning, and professional attitude. Among these categories, integrated knowledge base $(34.68 \%)$ and professional attitude $(2.31 \%)$ were the categories mentioned most and least frequently.

Conclusion: The findings of this study provide an overall understanding of the learning experience of Korean medical students during PBL in terms of what they learned and how they learned with rich descriptive commentaries from their perspectives as well as several thoughtful insights to help develop instructional strategies to enhance the effectiveness of PBL.

Key Words: Reflection, Problems-based learning, Content analysis

\section{Introduction}

Reflection is a purposeful critical analysis of knowledge and learning experience to achieve deeper understanding in learning processes. Students in a problembased learning (PBL) environment have to deal with an authentic problem or clinical case and engage reflectively with it in order to construct their own understanding [1]. In PBL, students should relate "their new knowledge to their prior understanding, attentively abstract knowledge, and understand how their learning and problem-solving strategies might be reapplied" [2]. These processes are supported through reflective thinking and reflecting on the relationship between problem solving and learning is a crucial component of PBL.

Reflective essays are often used in PBL to promote and externalize students' reflection on learning experiences. Through writing reflective essays about what they understood and how they learned at the completion of PBL, students can make inferences that tie general concepts and skills to the specifics of the problems under discussion [3]. As a result, they can construct a more coherent understanding. Thus, a reflective essay is
Received: October 10, 2017 • Revised: November 20, 2017 • Accepted: December 7, 2017 Corresponding Author: Jihyun Si (https://orcid.org/0000-0002-4782-6104)

Department of Medical Humanities, Dong-A University College of Medicine, 32 Daesingongwon-ro, Seo-gu, Busan 49201, Korea

Tel: +82.51.240.2617 Fax: +82.51.240.2617 email: jennyhan0306@gmail.com
Korean J Med Educ 2018 Mar; 30(1): 57-64.

https://doi.org/10.3946/kjme.2018.82

eISSN: 2005-7288

(C) The Korean Society of Medical Education. All rights reserved. This is an open-access article distributed under the terms of the Creative Commons Attribution Non-Commercial License (http:// creativecommons.org/licenses/by-nc/3.0/), which permits unrestricted non-commercial use, distribution, and reproduction in any medium, provided the original work is properly cited. 
itself an effective learning strategy to promote reflection and at the same time can be a tool for assessing their learning experience during PBL [4].

Many studies have explored medical students' learning experience in PBL, but they have mainly been quantitative, focusing on measuring the effectiveness of PBL compared with conventional teaching methods [5]. Little research has been conducted to qualitatively explore their PBL experience [6]. In addition, almost no research has been conducted to explore their learning experience by analyzing their reflective essays particularly in Korean medical schools. Quantitative research cannot normally provide information about what they learned or felt and how they learned during PBL. Analyzing reflective essays qualitatively can provide richly descriptive information about the learning experience of medical students in PBL from their perspective. Therefore, this study aimed to explore the learning experience in PBL particularly in terms of what they learned and how they learned in one Korean medical school by analyzing their reflective essays with qualitative research methods. Understanding their learning experiences in PBL with in-depth, textualized data can provide thoughtful insights for the development of effective instructional strategies to enhance the effectiveness of PBL.

\section{Methods}

\section{Participants}

The subjects of this study were first-year medical students enrolled in the three consecutive PBL courses at Dong-A University College of Medicine in Korea during the fall semester of 2015. These students consented to the collection of data. Among the 49 students in the classes, five students who did not participate in the entire series of three PBL courses were excluded, leaving 44 first-year students who participated in this study (29 male and 15 female). Their ages ranged from 21 to 33 years (mean \pm standard deviation $=24 \pm 2.43$ ). The students in the PBL courses were randomly assigned to discussion groups of seven or eight. They had not taken PBL courses before the first PBL course.

\section{Problem-based learning}

The PBL courses in this study consisted of three meetings for 3 weeks. In the first two meetings, the seven or eight students of a group discussed a case together with a tutor for about 120 minutes at a time. A typical PBL course started with the tutor presenting a patient's main symptoms to the students, who then generated multiple hypotheses based on the patient's main symptoms, gathered relevant data from the tutor, and at the end of the first meeting identified learning issues for self-directed learning. In the second meeting, they shared the information they gathered during self-directed learning, reviewed their prior hypotheses based on new information, and decided which hypothesis was accepted as a final diagnosis. In doing so, the students were asked to construct concept maps of their argumentation based on Toulmin's argument model [7].

In the third meeting, all the students gathered in one classroom with the professor who developed the PBL module and each group presented its concept map. The professor gave feedback on their presentations and delivered a final mini-lecture. The clinical case for the first PBL was of a 2-year-old girl suffering from barking coughing, hoarseness, and difficult breathing. The case for the second PBL was of an unconscious 55-year-old man and the case for the third PBL was of a 73-year-old man suffering from edema. 


\section{Procedures}

Before the PBL sessions, students and tutors were given a PBL orientation session, and these orientation sessions were mandatory for both students and tutors. The first PBL session proceeded at the beginning of the fall semester and the second session proceeded 5 weeks later, while the third PBL proceeded in March of the next year. The students were asked to write reflective essays about their PBL learning experience in terms of what they understood and how they learned after a mini-lecture in the third meeting of each PBL course. Thus, in total, they wrote reflective essays three times and they wrote them anonymously.

\section{Analysis}

The students wrote 107 essays in total as some of them did not write the reflective essays; 39 in the first PBL, 28 in the second PBL, and 40 in the third PBL wrote the reflective essays. Their reflective essays were analyzed with an inductive content analysis method [8]. The purpose of this study was to explore medical students' learning experience in PBL, so coded categories should be derived directly from the text data. Thus, inductive analysis was utilized. In order to systematically analyze reflective essays, NVIVO 11, qualitative research software developed by QSR International, was utilized (QSR International, Doncaster, Australia). Using this software, the data were first coded using open coding techniques [8], which entailed assigning headings to all the data. The reflective essays were read through again and as many headings as necessary were assigned to describe all aspects of the content, after which related headings were combined into higher-order heading. The related higher-order coding was then grouped as sub-categories. The sub-categories with similar events are grouped as categories. Through this abstraction process [8], each category revealed the distinctive characteristics of PBL learning experience. These categories were reviewed by another expert in the field of education technology and if there was disagreement between the researcher and the second expert, the categories were modified based on their consensus. The final findings were also calculated with frequency using IBM SPSS ver. 23.0 (IBM Corp., Armonk, USA).

\section{Results}

The coding process yielded sixteen sub-categories and these categories were grouped into six categories according to the distinctive characteristics of PBL learning experience: integrated knowledge base, clinical problem solving, collaboration, intrinsic motivation, self-directed learning, and professional attitude. Among these categories, integrated knowledge base (34.68\%) and professional attitude $(2.31 \%)$ were the categories mentioned most and least frequently, respectively. Table 1 shows the frequency with which each category occurred.

Regarding the category of integrated knowledge base, the findings generally indicate that the medical students recognized those authentic learning experiences during PBL as valuable that dealt with real clinical cases as doctors do. They also perceived that they could remember what they learned through PBL longer than what they learned in class. In addition, many of them reported that they felt a lack of medical knowledge. Regarding the category of clinical problem solving, the findings generally illustrate that while they were involved in clinical problem solving, they recognized their lack of problem-solving skills and understood they should not abandon their initial hypotheses without very strong evidence. Regarding the category of collaboration, 
Table 1. Frequency and Ratio of Each Category of the Data

\begin{tabular}{|c|c|c|}
\hline Category & №. $(\%)$ & Total no. $(\%)$ \\
\hline Integrated knowledge base & & $60(34.68)$ \\
\hline Recognizing authentic learning experiences as valuable & $25(14.45)$ & \\
\hline Recognizing a lack of medical knowledge & $23(13.29)$ & \\
\hline Acquiring medical knowledge & $7(4.05)$ & \\
\hline Remembering what I learn for a long time & $5(2.89)$ & \\
\hline Clinical problem solving & & 56 (32.37) \\
\hline Recognizing the risk of hasty decision & $20(11.56)$ & \\
\hline Understanding the clinical problem-solving process & $17(9.83)$ & \\
\hline Acquiring clinical problem-solving skills & $15(8.67)$ & \\
\hline Recognizing a lack of problem-solving skills & $4(2.31)$ & \\
\hline Collaboration & & $24(13.86)$ \\
\hline Understanding the effectiveness of collaboration & $18(10.40)$ & \\
\hline Recognizing poor communication skills & $3(1.73)$ & \\
\hline Promoting active participation & $3(1.73)$ & \\
\hline Intrinsic motivation & & $15(8.67)$ \\
\hline Increasing interest in learning & $15(8.67)$ & \\
\hline Self-directed learning & & $14(8.10)$ \\
\hline Acquiring self-directed learning skills & $7(4.05)$ & \\
\hline Inducing active learning & $5(2.89)$ & \\
\hline learning from various sources & $2(1.16)$ & \\
\hline Professional attitude & & $4(2.31)$ \\
\hline Reflecting on the professional attitude of doctors & $4(2.31)$ & \\
\hline
\end{tabular}

Table 2. The Examples of the Contents of the Reflective Essays Corresponding to Each Category

\begin{tabular}{|c|c|}
\hline Category & References \\
\hline \multicolumn{2}{|l|}{ Integrated knowledge base } \\
\hline $\begin{array}{l}\text { Recognizing authentic } \\
\text { learning experiences as } \\
\text { valuable }\end{array}$ & $\begin{array}{l}\text { I did not realize before that I was actually learning to use the knowledge. I got the impression that I was } \\
\text { actually doing medical practice rather than merely acquiring knowledge in PBL. } \\
\text { I have had a very valuable experience in dealing with a real case and through PBL I was able to see how } \\
\text { to apply what I learned when seeing real patients. }\end{array}$ \\
\hline $\begin{array}{l}\text { Recognizing a lack of medical } \\
\text { knowledge }\end{array}$ & $\begin{array}{l}\text { I realized that I knew nothing. } \\
\text { I tried to make more comments when we set hypotheses, but I realized that I still lacked medical knowledge. }\end{array}$ \\
\hline Acquiring medical knowledge & $\begin{array}{l}\text { I became aware of symptoms and treatments for drug addiction. } \\
\text { I realized that there were the other causes of edema than kidney, heart, and liver disease. }\end{array}$ \\
\hline $\begin{array}{l}\text { Remembering what I learn for } \\
\text { a long time }\end{array}$ & $\begin{array}{l}\text { I felt that I could remember what I learned in the PBL course for a long time as I did not just listen to } \\
\text { lectures. I normally do not review the contents of the class and then soon forget them, but the knowledge } \\
\text { acquired through this PBL course seems like it will not be forgotten for a long time. }\end{array}$ \\
\hline \multicolumn{2}{|l|}{ Clinical problem solving } \\
\hline $\begin{array}{l}\text { Recognizing the risk of a hasty } \\
\text { decision }\end{array}$ & $\begin{array}{l}\text { I learned that even if the probability is low, I should not dismiss a certain hypothesis without data that can } \\
\text { reject the hypothesis for sure. } \\
\text { I found that the hypothesis that I was sure of at the beginning could not be the answer. }\end{array}$ \\
\hline $\begin{array}{l}\text { Understanding clinical } \\
\text { problem-solving process }\end{array}$ & $\begin{array}{l}\text { I learned that it is important to understand the situation of the patient and listen to the witnesses and the } \\
\text { guardians'statements rather than merely start with tests. } \\
\text { Because there was no particular evidence suggestive of a specific disease in the results of various tests, it } \\
\text { was difficult to access the underlying cause of the disease. It was like solving a problem without an answer. }\end{array}$ \\
\hline $\begin{array}{l}\text { Acquiring clinical } \\
\text { problem-solving skills }\end{array}$ & $\begin{array}{l}\text { The PBL provided a glimpse into the diagnostic process. Through PBL, I learned the process of arriving at } \\
\text { a diagnostic decision by applying existing knowledge and studying the necessary knowledge. } \\
\text { Before making a diagnosis, I realized it is always a good idea to review clinical problem-solving processes } \\
\text { logically, and once again I realized the importance of clinical problem-solving skills. }\end{array}$ \\
\hline
\end{tabular}




\begin{tabular}{|c|c|}
\hline Category & References \\
\hline $\begin{array}{l}\text { Recognizing a lack of } \\
\text { problem-solving skills }\end{array}$ & $\begin{array}{l}\text { I thought that I should be more familiar with the process of problem solving. I needed more training to acquire } \\
\text { clinical problem-solving skills. }\end{array}$ \\
\hline \multicolumn{2}{|l|}{ Collaboration } \\
\hline $\begin{array}{l}\text { Understanding the } \\
\text { effectiveness of } \\
\text { collaboration }\end{array}$ & $\begin{array}{l}\text { I felt that collaborating with my colleagues was very important to my life as a physician, as the doctors in } \\
\text { various departments have to collaborate in order to solve a clinical case. } \\
\text { I have considered various diseases, but when I heard the other groups'presentation, it seemed to be an opportunity } \\
\text { to broaden my point of view by considering other directions. }\end{array}$ \\
\hline $\begin{array}{l}\text { Recognizing poor } \\
\text { communication skills }\end{array}$ & $\begin{array}{l}\text { I was accustomed to talking, and found out that I am not good at listening to others' thoughts. } \\
\text { I felt it is important to deliver my thought logically and explain my points well. I think I need training in communication } \\
\text { skills to be a better discussant. }\end{array}$ \\
\hline $\begin{array}{l}\text { Promoting active } \\
\text { participation }\end{array}$ & $\begin{array}{l}\text { In PBL, I felt that I should not only share my thoughts with the person next to me, but also express them } \\
\text { to a group as a whole. I felt I should participate more actively in discussion. }\end{array}$ \\
\hline \multicolumn{2}{|l|}{ Intrinsic motivation } \\
\hline Increasing interest in learning & $\begin{array}{l}\text { It was a fresh shock to me to actively get involved in discussions and learn from them. It was interesting } \\
\text { to generate and accept or reject hypotheses along the way through logical thinking processes. } \\
\text { In the case of an emergency like this case, I heard I should judge the cause within } 5 \text { minutes and treat it. } \\
\text { I will study hard so that I can make judgement immediately. }\end{array}$ \\
\hline \multicolumn{2}{|l|}{ Self-directed learning } \\
\hline $\begin{array}{l}\text { Acquiring self-directed } \\
\text { learning skills }\end{array}$ & $\begin{array}{l}\text { I looked for something that I did not know but was curious about during the problem-solving process. This } \\
\text { learning method is very effective. } \\
\text { During the PBL class, the self-directed learning for group work was very useful and I learned a lot from it. }\end{array}$ \\
\hline Inducing active learning & $\begin{array}{l}\text { I searched for information which I did not know before class, so I got more actively involved in the learning } \\
\text { process. } \\
\text { I got to understand what I did not know related to the case under discussion. Thus, I could study what I } \\
\text { did not know and in doing so, I become more active. }\end{array}$ \\
\hline $\begin{array}{l}\text { Learning from various } \\
\text { resources }\end{array}$ & $\begin{array}{l}\text { During PBL, I read the materials that I searched for through websites that doctors made or through papers } \\
\text { that doctors wrote rather than textbooks, and I applied what I read to solve the case. } \\
\text { I learned a lot by preparing appropriate reference materials that my team would use to solve the case. }\end{array}$ \\
\hline \multicolumn{2}{|l|}{ Professional attitude } \\
\hline $\begin{array}{l}\text { Reflecting on the professional } \\
\text { attitude of doctors }\end{array}$ & $\begin{array}{l}\text { I reflected deeply on the attitude of the practitioner through a real misdiagnosis case. I should not be too } \\
\text { stubborn in my decision. } \\
\text { If I make a wrong diagnosis, I should acknowledge it instantly and offer a patient proper treatment. }\end{array}$ \\
\hline
\end{tabular}

PBL: Problem-based learning.

the findings generally illustrate that the students felt how effective or important collaboration was in terms of solving a clinical case. They also thought that collaboration promoted their active participation, but that their poor communication skills were a hindrance to effective collaboration. Regarding the category of self-directed learning, they mentioned that the process of searching for what they did not know but needed to know related to the clinical case was very useful for their learning and through this self-directed learning process, they were actively engaged in learning and had learned from various resources. In addition, they expressed that the PBL process increased their interest in learning and made them ponder the professional attitude of a doctor, such as what they should do as a professional practitioner when they make mistakes. Table 2 presents examples of the contents of the reflective essays corresponding to each category.

\section{Discussion}

This study analyzed Korean medical students' reflective essays using a qualitative research method to explore their' learning experience in PBL from their voice. The category, "recognizing authentic learning 
experiences as valuable" was the most occurring category. An authentic learning experience is one of the distinctive essential characteristics of PBL and the students clearly recognized it as valuable. Through dealing with a clinical case, students can construct an integrated knowledge base across multiple disciplines, and such a knowledge base can enhance their ability to recall what they have learned and apply it to clinical work [9]. This finding is the same to that of Choi et al. [10] reporting that nursing students expressed the view of the authentic learning experience in PBL as very useful and valuable.

Regarding clinical problem-solving skills, the findings showed that PBL have positive effects of developing their clinical problem-solving skills. In fact, whether students acquire clinical problem-solving skills during PBL are not conclusive according to the previous research [10-12]. However, their statements are in agreement with studies showing positive effects on this issue [10,11]. Regarding collaboration, the findings showed that the students understood how important it is for successful problem solving that they function well as part of team and that there is a smooth open exchange of ideas and active engagement by all members of a group. In fact, there was little research conducted regarding effects of PBL on developing collaboration skills. This result showed that PBL is an effective method for developing collaboration skills and this result is consistent with that of L'Ecuyer et al. [13], which reported that nursing students expressed PBL as an effective method for developing collaboration skills in their reflective essays.

Students are more motivated when they feel what they are learning is valuable to them [2]. As expected according to the result, as solving a real clinical case was a valuable experience to them, their motivation toward learning was enhanced. This result is in the same vein as other research indicating that PBL improves students' motivation toward learning [6,11]. One of the goals of PBL is to develop self-directed learning skills. The students reported that they developed self-directed learning skills through PBL, and this result is the same as that of other studies reporting positive effects of PBL on self-directed learning [10]. Finally, the students also commented on professional attitudes. One of the clinical cases discussed during PBL in this study concerned a girl who had been previously hospitalized 8 times due to misdiagnosis. Through this case, the students pondered what they should do when they misdiagnose a patient. The demonstration of an appropriate professional attitude is a critical skill in the field of heath science, and the results indicate that PBL can be a useful tool for developing the professional attitudes of medical students.

These findings suggest several instructional strategies. First, the authentic learning afforded by PBL was most frequently mentioned in the reflective essays and the medical students recognized it as valuable. Thus, as authentic learning is a key component of successful PBL, a clinical case provided to students should be carefully designed. A good clinical case should be realistic, allows students to evaluate the effectiveness of their knowledge, requires multidisciplinary solutions, fosters communication skills as they exchange their opinions, and motivate their need to know and learn [2]. Secondly, the medical students mentioned that their poor communication skills were a hindrance to their active participation in collaborating with others. Listening to others and expressing one's opinion logically are essential components of successful collaboration. Thus, training in communication skills before PBL can be an effective strategy for enhancing the effectiveness of collaboration. Thirdly, they also expressed their lack of problem-solving skills and their need for such training. Thus, a workshop session offering training in problem-solving skills 
before PBL can help them develop effective clinical problem-solving skills. Lastly, this study shows that PBL can be used in the development of the professional attitudes of medical students, which is an important objective of medical education. In order to do so, they must reflect on how they respond to difficult situations, and PBL can provide this opportunity with a welldesigned clinical case.

This study has limitations. The reflective essays that were analyzed were collected after three PBL courses. Although they were conducted consecutively, there were intervals between them. Thus, the possibility was not entirely excluded that this interval might have influenced the contents of the reflective essays. Furthermore, a study qualitatively exploring how medical students apply the knowledge and skills acquired from the PBL experience in their clinical practices is needed to confirm and deepen the results of this study.

In conclusion, the findings of this study provide an overall understanding of the learning experience of Korean medical students during PBL particularly in terms of what they learned and how they learned with rich descriptive commentaries from their perspectives as well as several thoughtful insights to help develop instructional strategies to enhance the effectiveness of PBL.

\section{ORCID:}

Jihyun Si: https://orcid.org/0000-0002-4782-6104

Acknowledgements: None.

Funding: This work was supported by the Dong-A University research fund.

Conflicts of interest: No potential conflict of interest relevant to this article was reported.

\section{References}

1. Lim LA. A comparison of students' reflective thinking across different years in a problem-based learning environment. Instr Sci. 2011;39(2):171-188.

2. Hmelo-Silver CE. Problem-based learning: what and how do students learn? Educ Psychol Rev. 2004;16(3):235266.

3. Xie Y, Ke F, Sharma P. The effect of peer feedback for blogging on college students' reflective learning processes. Internet High Educ. 2008;11(1):18-25.

4. Kang I, Jung ES. The reexamination of educational implications of reflective journals: a university class case. Korean J Educ Methodol Stud. 2009;21(2):93-117.

5. Moon JA. Learning journals: a handbook for academics, students and professional development. London, UK: Routledge Falmer; 1999.

6. Hwang SY, Jang KS. Perception about problem-based learning in reflective journals among undergraduate nursing students. J Korean Acad Nurs. 2005;35(1): 65-76.

7. Toulmin SE, Rieke RD, Janik A. An introduction to reasoning. 2nd ed. New York, USA: Macmillan; 1984.

8. Elo S, Kyngäs $\mathrm{H}$. The qualitative content analysis process. J Adv Nurs. 2008;62(1):107-115.

9. Barrows HS. Problem-based learning in medicine and beyond: a brief overview. New Dir Teach Learn. 1996; 1996(68):3-12.

10. Choi E, Lindquist R, Song Y. Effects of problem-based learning vs. traditional lecture on Korean nursing students' critical thinking, problem-solving, and self-directed learning. Nurse Educ Today. 2014;34(1):52-56.

11. Klegeris A, Hurren H. Impact of problem-based learning in a large classroom setting: student perception and problem-solving skills. Adv Physiol Educ. 2011;35(4): 408-415. 
12. Choi H. The effects of PBL (problem-based learning) on the metacognition, critical thinking, and problem solving process of nursing students. J Korean Acad Nurs. 2004; 34(5):712-721.
13. L'Ecuyer KM, Pole D, Leander SA. The use of PBL in an interprofessional education course for health care professional students. Interdiscip J Probl Based Learn. 2015;9(1):9-18. 